\title{
Virtual Reality and the future of construction
}

\begin{abstract}
Adeeb Sidani $^{1}$, J. Duarte ${ }^{2}$, Fábio Dinis ${ }^{3}$, Luís Sanhudo ${ }^{4}$, J. Santos Baptista ${ }^{5}$, João Poças Martins ${ }^{6}$, Alfredo Soeiro ${ }^{7}$
${ }^{1}$ Faculty of Engineering, University of Porto, PT (adeeb.sidani@hotmail.com), ${ }^{2}$ Associated Laboratory for Energy, Transports, and Aeronautics (PROA/LAETA), Faculty of Engineering, University of Porto, PT (jasduarte@fe.up.pt) ORCID 0000-0002-5856-5317, ${ }^{3}$ CONSTRUCT GEQUALTEC, Faculty of Engineering, University of Porto, PT (fabiodinis@fe.up.pt), ${ }^{4}$ CONSTRUCT - GEQUALTEC, Faculty of Engineering, University of Porto, PT (Ipnsanhudo@fe.up.pt) ORCID 000-0002-2578-6981, ${ }^{5}$ Associated Laboratory for Energy, Transports and Aeronautics (PROA/LAETA), Faculty of Engineering, University of Porto, PT (jsbap@fe.up.pt) ORCID 0000-0002-8524-5503, ${ }^{6} \mathrm{CONSTRUCT} \mathrm{-} \mathrm{GEQUALTEC}$ Faculty of Engineering, University of Porto, PT (jppm@fe.up.pt), ${ }^{7}$ Faculty of Engineering, University of Porto, PT (avsoeiro@fe.up.pt) https://doi.org/10.24840/978-972-752-260-6_0046-0050
\end{abstract}

\begin{abstract}
Introduction: Despite the recent trends in technology, construction projects are becoming increasingly challenging, which, in the result, brings in more complex and dynamic construction environments. In fact, traditional management and monitoring methods are currently unable to keep up with the industry's quick development, leading to several problems in task efficiency and transfer of information between stakeholders. As a result, the Architecture Engineering Construction and Operations (AECO) sector is making use of the digitalization in order to improve project management, assist trade-crews and achieve a more proficient working environment. The adoption of Building Information Modelling (BIM) embodies a paradigm shift from the traditional approaches towards a collaborative and integrated working process. Though BIM is improving the aforesaid issues, not every construction entity can easily adapt and use it successfully. Therefore, supportive tools to assist BIM in achieving its full potential are in high demand. Objectives: The current research objective is to provide a review of previous works in the field of BIM-based Virtual Reality (VR), in order to establish a clear view of this research field. This work provides the primary data on such goals. Methodology: In order to conduct the research, the PRISMA Statement strategy was used. The selected primary keywords were "construction", "virtual reality" and "building information modelling " and their variants. The research was carried out in the main engineering databases and journals, being Scopus, Science Direct and IEEE Xplore some examples. Results: After the identification of 2,950 records, exclusion criteria were applied: year of publication, type of document, type of source and deduplication. The titles and abstracts of the publications were screened in order to determine the scope of the papers, leaving for full-text analysis just 75 studies. After going through the eligibility criteria, only 14 papers remained. Using the snowballing technique, two more papers were added to the study, resulting in 16 included papers. Most of the papers focused on the Construction Design, Construction Management, and Construction Safety fields, being "design" the most occurring construction stage. The highlighted target groups for the VR interfaces were Engineers, Architects and Workers. Most system architectures comprise, at least, three layers regarding a BIM software tool, a visual enhancement module and a game engine to provide the virtual environment and interaction functionalities. However, some studies referred to a fourth layer (database). Conclusions: The BIM-VR relation addressed in the articles was mainly focused on the model's geometric information since BIM provides an accurate display of building geometry. Most VR interfaces do not possess a database component to provide access to BIM parametric information, leading to the conclusion that BIM is not achieving its full potential with VR tools.
\end{abstract}

Keywords: Construction, Digitalization, Interface, Virtual Reality, BIM.

\section{INTRODUCTION}

The Architecture Engineering Construction and Operations (AECO) sector is continuously faced with increasingly complex and competitive projects (Chan, Scott, and Chan 2004, Pham et al. 2017). To this end, the dissemination and implementation of Building Information Modelling (BIM) in the last few years contributed to pursue higher performance and accuracy in its processes through the digitalization (Antwi-Afari et al. 2018, Li et al. 2017, Succar 2009). BIM supports information creation, management, storage and exchange, and has the ability to apply it to a buildings' lifecycle (Sanhudo et al. 2018). However, the uptake rate of BIM has been slower than originally expected (Walasek and Barszcz 2017), as users lack the knowledge to take full advantage of its potential for communication (amongst project teams), exportation and visualization of the project, among others. On the other hand, Virtual Reality (VR) has shown encouraging developments, showing potential benefits with diverse applications, especially when taking advantage of accuracy and information comprised in BIM models (Li et al. 2017). Therefore, BIM-based VR applications have shown many advantages to boost design review, team collaboration, decision making, among others. As such, the goal of this short paper is to provide the primary data results analysis concerning recent advances in this field, enabling a 
clear view of the research the sector produced in generating immersive VR environments from BIM.

\section{METHODOLOGY}

The study methodology was based on the systematic review protocol of Sidani et al. (Sidani et al. 2018), where the Preferred Reporting of Items for Systematic Reviews and Meta-Analyses (PRISMA) guidelines were used (Moher et al. 2009). The following databases and journals were screened: Academic Search Complete, Current Contents, Web of Science, SCOPUS, INSPEC, ScienceDirect, Cambridge Journals Online, Directory of Open Access Journals, Emerald Fulltext, Informaworld (Taylor and Francis), Oxford Journals, SAGE Journals Online, Scientific Electronic Library Online, SpringerLink, Wiley Online Library, ACM Digital Library, ASME Digital Collection, CE Database (ASCE), IEEE Xplore, IOP Journals, ScienceDirect (eJournals), and SIAM. The core keywords were "construction", "virtual reality" and "building information modeling". However, keyword variations were also used.

\section{RESULTS AND DISCUSSION}

A total of 2,950 records were identified through database searching. Then, applying the exclusion criteria, 748 were excluded by date (prior 2007), 957 by type of article (reviews, book chapters), 375 by type of source (apart from trade publications), and 18 due to language (other than English). Title and abstracts were screened, leading to the rejection of 464 papers (off topic) and an additional 313 records (duplicates) were removed. The 75 remaining papers were fulltext screened in order to conduct the eligibility criteria phase. Only 14 papers remained after both screening processes. A final search was performed on the references of the articles that achieved the inclusion criteria stage. From this new search, two new articles were added to the research, resulting in a total of 16 articles. The summary of the research can be observed in Figure 1.

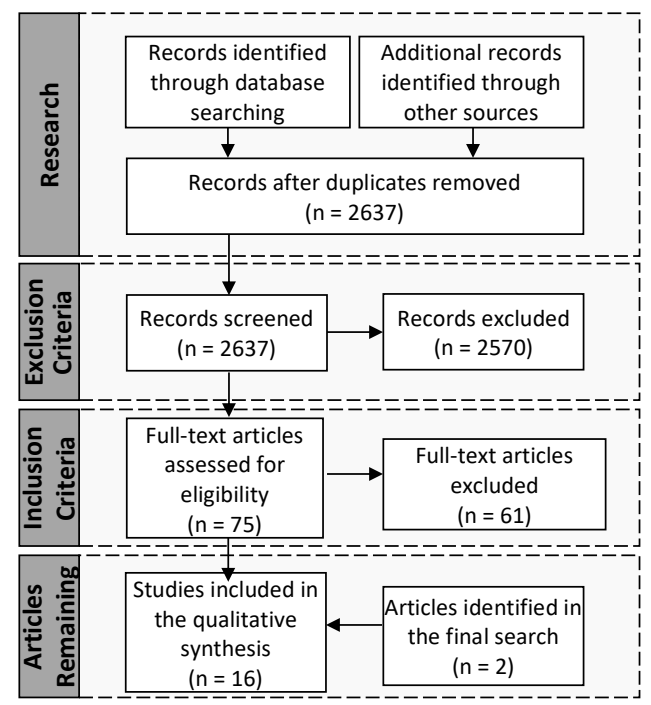

Figure 1. Research strategy based in PRISMA Statement

Most of the 16 (Table 1) selected studies focused on enhancing teamwork, communication and cross-team interaction, which is a common objective for VR related articles in general. The highlighted fields were Construction Design, Construction Management, and Construction Safety and the most occurring construction stage was design. As for the target groups, the 
available research showed that Engineers, Architects, and Workers are typically the target users for the VR interfaces.

Table 1. Selected articles' construction stage, targeted group and researched BIM dimension

\begin{tabular}{|c|c|c|c|}
\hline Author & Construction Stage & Target Group & $\begin{array}{l}\text { BIM } \\
\text { Dimension }\end{array}$ \\
\hline (Lin, Chen et al. 2018) & - Design & $\begin{array}{l}\text { - Owners } \\
\text { - Architects } \\
\text { - Engineers }\end{array}$ & - 3D \\
\hline (Boton 2018) & $\begin{array}{l}\text { - Design } \\
\text { - Pre-construction } \\
\text { - Construction }\end{array}$ & $\begin{array}{l}\text { - Owners } \\
\text { - Architects } \\
\text { - Engineers } \\
\text { - Workers }\end{array}$ & $\begin{array}{l}\text { - } 3 \mathrm{D} \\
\text { - } 4 \mathrm{D}\end{array}$ \\
\hline (Wang, Li et al. 2018) & - Design & $\begin{array}{l}\text { - Engineers } \\
\text { - Students }\end{array}$ & $\begin{array}{l}\text { - } 3 D \\
\text { - } 5 \mathrm{D} \\
\text { - } 7 \mathrm{D}\end{array}$ \\
\hline (Du, Shi et al. 2017) & $\begin{array}{l}\text { - Design } \\
\text { - Pre-construction } \\
\text { - Construction } \\
\text { - Operation and } \\
\text { management }\end{array}$ & $\begin{array}{l}\text { - Owners } \\
\text { - Architects } \\
\text { - Engineers } \\
\text { - Workers } \\
\text { - Facility managers }\end{array}$ & $\begin{array}{l}\text { - } 3 \mathrm{D} \\
\text { - } 4 \mathrm{D} \\
\text { - } 5 \mathrm{D} \\
\text { - } 6 \mathrm{D} \\
\text { - } 7 \mathrm{D}\end{array}$ \\
\hline (Cárcamo, Trefftz et al. 2017) & - Design & $\begin{array}{l}\text { - Owners } \\
\text { - Architects } \\
\text { - Engineers }\end{array}$ & - 3D \\
\hline (Jensen 2017) & - Design & - Students & - 3D \\
\hline (Azhar 2017) & $\begin{array}{l}\text { - Pre-construction } \\
\text { - Construction }\end{array}$ & $\begin{array}{l}\text { - Engineers } \\
\text { - Workers }\end{array}$ & $\begin{array}{l}\text { - } 3 \mathrm{D} \\
\text { - } 4 \mathrm{D}\end{array}$ \\
\hline (Wu, Wu et al. 2017) & - Design & - Students & - $3 \mathrm{D}$ \\
\hline (Natephra, Motamedi et al. 2017) & - Design & $\begin{array}{l}\text { - Owner } \\
\text { - Architects } \\
\text { - Engineers }\end{array}$ & $\begin{array}{l}\text { - } 3 \mathrm{D} \\
\text { - } 5 \mathrm{D}\end{array}$ \\
\hline (Shi, Du et al. 2016) & $\begin{array}{l}\text { - Operation and } \\
\text { management }\end{array}$ & $\begin{array}{l}\text { - Facility managers } \\
\text { - Users }\end{array}$ & $\begin{array}{l}\text { - } 3 \mathrm{D} \\
\text { - } 6 \mathrm{D} \\
\end{array}$ \\
\hline (Hilfert and König 2016) & $\begin{array}{l}\text { - Design } \\
\text { - Construction }\end{array}$ & $\begin{array}{l}\text { - Architects } \\
\text { - Engineers } \\
\text { - Workers }\end{array}$ & $\begin{array}{l}\text { - } 3 \mathrm{D} \\
\text { - } 4 \mathrm{D}\end{array}$ \\
\hline (Edwards, Li et al. 2015) & - Design & - Users & - 3D \\
\hline (Sacks, Whyte et al. 2015) & $\begin{array}{l}\text { - Design } \\
\text { - Construction }\end{array}$ & $\begin{array}{l}\text { - Architects } \\
\text { - Engineers } \\
\text { - Workers }\end{array}$ & $\begin{array}{l}\text { - } 3 \mathrm{D} \\
\text { - } 4 \mathrm{D}\end{array}$ \\
\hline (Gurevich and Sacks 2014) & - Construction & - Workers & $\begin{array}{l}\text { - } 3 \mathrm{D} \\
\text { - } 4 \mathrm{D}\end{array}$ \\
\hline (Wang, Li et al. 2014) & $\begin{array}{l}\text { - } \text { Design } \\
\text { - Operation and } \\
\text { management }\end{array}$ & - Users & $\begin{array}{l}\text { - } 3 \mathrm{D} \\
\text { - } 4 \mathrm{D} \\
\text { - } 6 \mathrm{D}\end{array}$ \\
\hline (Sacks, Gurevich et al. 2013) & - Construction & - Workers & $\begin{array}{l}\text { - } 3 \mathrm{D} \\
\text { - } 4 \mathrm{D}\end{array}$ \\
\hline
\end{tabular}

Regarding the hardware and software uses, most system architectures comprise at least three noteworthy layers:

- a BIM software tool, to provide an accurate 3D representation of the building in the study; 
- a visual enhancement module, for compatibility between game engines and BIM authoring tools, model optimization and visual improvement;

- and a game engine, to provide the immersive virtual environment and interaction functionalities.

Finally, some studies expand to a fourth layer, including a database component to access the model's parametric information. Regarding validation, the greater part of the authors conducted case studies to test their proposed interfaces. However, among the 12 case studies found, six were combined with questionnaires and three mentioned conducting pilot tests. Overall, it was not found a holistic methodology or assessment framework towards the validation of BIM-based VR interfaces. Although quite a few limitations are offered regarding the use of VR laboratory experiments in opposition to field trials, the authors concluded that the use of VR increased both the reliability and the accuracy of the experimental results, as well as reduced the time needed to perform the experiment. It should be stated that while authors reinforce most of their choices throughout the studies, there exists a noticeable lack of information on the applied software. That is, despite the fact that the performance of most VR interfaces is directly dependent on the specifications of the equipment being used.

\section{CONCLUSIONS}

The essential idea behind the reviewed virtual reality applications is to enable collaboration and communication, allowing people with different expertise to access BIM information. Most of the BIM-based VR applications use a three-layer system architecture compromised of a BIM authoring tool, a game engine, and a visual enhancement module. Some studies expanded to a fourth layer (database) in order to exchange the non-geometric information. A great part of the studies lack a complete justification concerning the reason for selecting the applied tools. Additionally, it should be stated that most papers did not provide hardware specification despite its potential impact on the system's performance. From the selected contributions it was concluded that the most researched stage of the projects' lifecycle was designed (the aim of 12 of 16 occurrences). Most interfaces were assessed by case studies, with half of these further supporting and validating the results with questionnaires. Additionally, three articles also conducted pilot tests to ease the user experience with the created VR interface. As seen in (Nielsen 1994), this approach is recommended when dealing with interfaces that mark a transition between more traditional approaches, in order to eliminate possible biases during the evaluation process created from the users' excessive effort with the innovative interface. The relation of BIM and VR in the articles was mainly focused on the model's geometric information since BIM provides an accurate display of building geometry. Most VR interfaces do not possess a database component to provide access to BIM parametric information, leading to the conclusion that BIM is not achieving its full potential with VR tools. As such, future research could focus on handling the non-geometric data provided by BIM within immersive VR interfaces.

\section{References}

Antwi-Afari, MF, H Li, EA Pärn, and DJ Edwards. 2018. "Critical success factors for implementing building information modelling (BIM): A longitudinal review." Automation in Construction 91:100-110.

Chan, Albert PC, David Scott, and Ada PL Chan. 2004. "Factors affecting the success of a construction project." Journal of construction engineering and management 130 (1):153-155. 
$\mathrm{Li}$, Xiao, Peng Wu, Geoffrey Qiping Shen, Xiangyu Wang, and Yue Teng. 2017. "Mapping the knowledge domains of Building Information Modeling (BIM): A bibliometric approach." Automation in Construction 84:195-206.

Moher, David, Alessandro Liberati, Jennifer Tetzlaff, and Douglas G Altman. 2009. "Preferred reporting items for systematic reviews and meta-analyses: the PRISMA statement." Annals of internal medicine 151 (4):264-269.

Nielsen, Jakob. 1994. Usability engineering: Elsevier.

Pham, Hai Chien, Akeem Pedro, Quang Tuan Le, Do-Yeop Lee, and Chan-Sik Park. 2017. "Interactive safety education using building anatomy modelling." Universal Access in the Information Society:1-17.

Sanhudo, Luís, Nuno MM Ramos, João Poças Martins, Ricardo MSF Almeida, Eva Barreira, M Lourdes Simões, and Vítor Cardoso. 2018. "Building information modeling for energy retrofitting-A review." Renewable and Sustainable Energy Reviews 89:249-260.

Sidani, Adeeb Ziad, J Duarte, Fábio Matoseiro Dinis, J Santos Baptista, João Poças Martins, and Alfredo Soeiro. 2018. "The Impact of BIM-based virtual and augmented reality interfaces on health and safety in construction projects: protocol for a systematic review." International Journal of Occupational and Environmental Safety 2 (1):67-74.

Succar, Bilal. 2009. "Building information modelling framework: A research and delivery foundation for industry stakeholders." Automation in construction 18 (3):357-375.

Walasek, Dariusz, and Arkadiusz Barszcz. 2017. "Analysis of the adoption rate of building information modeling [BIM] and its return on investment [ROI]." Procedia Engineering 172:1227-1234. 